therefore quoted confidence intervals calculated by the standard simple formula.

1 Social Services Committee. Problems associated with AIDS. Vol 1. Third report from the House of Commons Social Services Committee 1986-1987. London: HMSO, 1987.

2 Advisory Council on the Misuse of Drugs. AIDS and drug misuse. Part 1. Report of the ACMD. London: HMSO, 1988.

3 Scottish Home and Health Department. HIV infection in Scotland. Report of the Scotish Committee on HIV Infection and Intravenous Drug Misuse. Edinburgh: SHHD, 1986.

4 Brettle RP, Nelles B. Special problems of injecting drug misusers. Br Med Bull 1988:44:149-60.

5 Mulleady G. A review of drug abuse and HIV infection. Psychological Health 1987:1:149-63.

6 Stimson G, Donoghoe M, Alldritt L, Dolan K. HIV transmission risk behaviour in clients attending syringe-exchange schemes in England and Scotland. Brf Addict 1988;83:1449-55.

7 Stimson GV, Alldritt L, Dolan K, Donoghoe M. Syringe exchange scheme for drug users in England and Scotland. Br Med f 1988;296:1717-9.

8 Scottish Home and Health Department. AIDS and drug misuse. Sale of injecting equipment by retail pharmacists. Edinburgh: SHHD, 1988. (NHS circular No 1988 (GEN) 19.)

9 Council of the Pharmaceutical Society of Great Britain. Sale of hypodermic syringes and needles. Council statement. Pharmaceutical foumal 1986;236:205.

10 Donoghoe MC, Stimson GV, Dolan K, Alldritt L. Changes in HIV risk behaviour in clients of syringe exchange schemes in England and Scotland. AIDS 1989;3:267-72.

11 Moser CA, Kalton G. Survey methods in social investigation. London: Heinemann, 1971.

(Acrepted 24 August 1989)

\section{Suprascapular nerve block for chronic shoulder pain in rheumatoid arthritis}

\section{Paul Emery, Simon Bowman, Lucy Wedderburn, Rodney Grahame}

\section{Department of}

Rheumatology, University

of Birmingham,

Birmingham B15 2TJ

Paul Emery, MRCP, senior

lecturer and consultant

\section{Department of}

Rheumatology, Guy's

Hospital, London

Simon Bowman, MRCP, senior house officer

Lucy Wedderburn, MRCP, senior house officer

Rodney Grahame, FRCP, consultant

Correspondence to: Dr Emery.

BrMed f 1989;299:1079-80

The shoulder is commonly affected in rheumatoid arthritis, which may lead to pain at rest and considerable morbidity.' Intra-articular injections can be used to treat isolated inflammation of the shoulder but are of dubious value in longstanding disease. The main sensory nerve to the shoulder, the suprascapular nerve, is accessible for percutaneous nerve block. ${ }^{2}$ This is performed routinely by anaesthetists and used commonly in pain clinics but is rarely performed by rheumatologists. We undertook a double-blind study to compare the suprascapular nerve block using steroid and bupivacaine with a conventional intra-articular injection of steroid and lignocaine.

\section{Patients, methods, and results}

We studied patients with rheumatoid arthritis according to the 1987 criteria of the American Rheumatism Association ${ }^{3}$ in whom both shoulders were painful and restricted in movement. The shoulders were randomised for severity. Patients received a suprascapular nerve block ( $40 \mathrm{mg}$ methylprednisolone mixed with $0.5 \%$ bupivacaine and adrenaline; total volume $2 \mathrm{ml}$ ) with a sham intra-articular injection in one shoulder. In the other shoulder they received a standard intra-articular injection $(40 \mathrm{mg}$ methylprednisolone plus $1 \%$ lignocaine; total volume $2 \mathrm{ml}$ ) with a sham suprascapular nerve block. Pain and stiffness were assessed on visual analogue scales, the pain index (a modified Ritchie index ${ }^{4}$ ) calculated, and movement assessed at $0,1,4$, and 12 weeks.

Twenty patients were recruited to the study; one was unsuitable and two were lost to follow up, so 17 patients ( 14 women) and 34 shoulders were available for follow up. All injections were performed by the same person (PE), and all assessments were performed blind by the same assessor. The patients had a mean age of 67 (range 53-84) and had had rheumatoid arthritis for 17 (4-29) years. Sixteen were positive for rheumatoid factor, eight had nodules, and 17 had erosions on radiography. The mean erythrocyte sedimentation rate was $48(3-91) \mathrm{mm}$ in the first hour.

The table shows the results of the treatments. The nerve block improved both pain and the pain index throughout the study, though the pain score was significantly improved only at one and four weeks and the pain index only at one week. The intra-articular injection resulted in a significant improvement in the pain score at one week but did not affect the pain index. After both injections stiffness was significantly im- proved only at one week. The nerve block produced a substantial improvement in abduction and flexion, though this was significant only for passive abduction at four weeks. The results of a questionnaire on activity did not alter during the study. At 12 weeks 12 patients thought that pain relief had been greater in the shoulder in which the nerve block had been performed and two that it had been greater in the shoulder in which intra-articular injection had been performed; three were undecided.

\section{Comment}

Compared with intra-articular steroid injection suprascapular nerve block resulted in significant benefits in terms of duration of pain relief, the pain index, and the range of movement. Stiffness improved for only one week, which suggests that the improvement in pain was unlikely to be a non-specific effect of steroids. Furthermore, the two injections produced different patterns of response.

The nerve block produced an improvement in movements of up to $20 \%$ in flexion and abduction. Active movement was greater than passive both before and after injection, possibly because protective spasm occurred when passive movement was attempted. Pain relief produced a greater improvement in passive

Effect of suprascapular nerve block and intra-articular injection of steroid on pain and stiffness in 17 patients with chronic shoulder pain in rheumatoid arthritis. Figures are mean $(S E)$ values

\begin{tabular}{|c|c|c|c|c|c|}
\hline & \multicolumn{4}{|c|}{ Weeks after injection } & \\
\hline & 0 & 1 & 4 & 12 & \\
\hline \multicolumn{5}{|l|}{ Paint: } & \\
\hline Nerve block & $59(7)$ & $33(8)^{\star \star \star}$ & $44(8)^{\star}$ & $47(9)$ & \\
\hline Intra-articular injection & $54(6)$ & $40(7)^{\star}$ & $47(9)$ & $53(9)$ & \\
\hline \multicolumn{5}{|c|}{ Pain index: } & \\
\hline Nerve block & $1 \cdot 52(0 \cdot 3)$ & $0.76(0 \cdot 2)^{\star}$ & $1.05(0 \cdot 3)$ & $1 \cdot 11(0 \cdot 2)$ & \\
\hline Intra-articular injection l & $11 \cdot 23(0 \cdot 3)$ & $1 \cdot 17(0 \cdot 4)$ & $1.41(0 \cdot 3)$ & $1.00(0.2)$ & \\
\hline \multicolumn{5}{|c|}{ Stiffnesst: } & \\
\hline Nerve block & $55(7)$ & $31(6)^{\star \star}$ & $53(7)$ & $56(9)$ & \\
\hline Intra-articular injection & $47(7)$ & $35(7)^{\star}$ & $44(9)$ & $55(9)$ & \\
\hline \multicolumn{5}{|c|}{$\begin{array}{l}\text { Movement (degrees): } \\
\text { Abduction: }\end{array}$} & \\
\hline \multirow{2}{*}{\multicolumn{5}{|c|}{$\begin{array}{l}\text { Abduction: } \\
\text { Active: }\end{array}$}} & \\
\hline & & & & & \\
\hline Nerve block & $53(5)$ & $60(5)$ & $61(5)$ & $54(5)$ & \\
\hline Intra-articular injection & $61(6)$ & $66(5)$ & $63(4)$ & $60(5)$ & \\
\hline \multicolumn{5}{|c|}{ Passive: } & \\
\hline Nerve block & $50(7)$ & $59(7)$ & $62(5)^{\star}$ & $55(5)$ & \\
\hline Intra-articular injection & $59(7)$ & $60(4)$ & $61(5)$ & $58(4)$ & \\
\hline \multirow{2}{*}{\multicolumn{5}{|c|}{$\begin{array}{l}\text { Flexion: } \\
\text { Active: }\end{array}$}} & \\
\hline & & & & & \\
\hline Nerve block & $67(6)$ & $78(7)$ & $74(4)$ & $68(7)$ & \\
\hline Intra-articular injection & $73(7)$ & $77(7)$ & $77(5)$ & $69(5)$ & \\
\hline \multicolumn{5}{|l|}{ Passive: } & \\
\hline Nerve block & $63(7)$ & $71(8)$ & $67(7)$ & $60(7)$ & \\
\hline Intra-articular injection & $71(8)$ & $75(8)$ & $67(7)$ & $66(8)$ & \\
\hline \multicolumn{5}{|c|}{ Rotation: } & \\
\hline \multicolumn{5}{|l|}{ Active: } & \\
\hline Nerve block & $36(6)$ & $33(4)$ & $35(4)$ & $30(4)$ & \\
\hline Intra-articular injection & $36(5)$ & $41(4)$ & $39(4)$ & $36(3)$ & \\
\hline \multicolumn{5}{|l|}{ Passive: } & \\
\hline Nerve block & $36(6)$ & $34(5)$ & $33(5)$ & $32(5)$ & \\
\hline Intra-articular injection & $36(5)$ & $42(4)$ & $35(4)$ & $36(4)$ & \\
\hline
\end{tabular}

Significance of difference in value from baseline value: ${ }^{\star} p<0 \cdot 05,{ }^{\star \star} p<0 \cdot 01$, $\star \star \star p<0.001$.

t Measured on visual analogue score $(0=$ none, $100=$ severe $)$. 
movement. Improvements in rotational movement were seen only with the intra-articular injection.

These results might be improved if patients with pain confined to the posterosuperior region of the shoulder, which is said to respond selectively to a nerve block, ${ }^{5}$ were treated.

1 Harris ED. Rheumatoid arthritis: the clinical spectrum. In: Kelly WN, Harri ED, Ruddy S, Sledge CB. Textbook of rheumatology. 3rd ed. Philadelphia: W B Saunders, 1989:930-1.
2 Eriksson E. Illustrated handbook of local anaesthesia. London: Lloyd Luke, 1979:85

3 Arnett FC, Edworthy SM, Bloch DA. The American Rheumatism Association, 1987. Revised criteria for the classification of rheumatoid arthritis. Arthritis Rheum 1988;31:315-23.

4 Ritchie DM, Boyle JA, McInnes JM, et al. Clinical studies with an articular index for the assessment of joint tenderness in patients with rheumatoid arthritis. Of Med 1968;147:393-406.

5 Brown DE, James DC, Roy S. Pain relief by suprascapular nerve block in glenohumeral arthritis. Scand f Rheumatol 1988;17:411-5.

(Accepted 24 fuly 1989)

\section{Cholestasis induced by oestrogen after liver transplantation}

\author{
Donna M Fedorkow, Bernard Corenblum, \\ Eldon A Shaffer
}

\section{Divisions of}

Gastroenterology and

Endocrinology,

Department of Medicine,

University of Calgary,

Calgary, Alberta, Canada

Donna M Fedorkow, FRCSC, resident

Bernard Corenblum, FRCPC, professor

Eldon A Shaffer, FRCPC professor

Correspondence to: $\operatorname{Dr} \mathrm{E} A$

Shaffer, Division of

Gastroenterology,

University of Calgary,

Calgary, Alberta T2N 4N1,

Canada.

BrMed f 1989;299:1080-1
Successful liver transplantation is not usually associated with hepatic dysfunction, though both low grade rejection and cyclosporin can induce cholestasis. ${ }^{.}$Natural and synthetic oestrogens also alter hepatic excretory function, occasionally inducing overt cholestasis in susceptible women. ${ }^{2}$ We report on a woman who developed cholestasis associated with oral oestrogen treatment after receiving an orthotopic liver transplant.

\section{Case report}

A 20 year old nulligravid woman had had well documented chronic active hepatitis since the age of 5 , which had been confirmed by liver biopsy. Other causes of chronic hepatitis had been excluded. Despite corticosteroid treatment for 12 years cirrhosis and oesophageal varices had developed, causing recurrent severe upper gastrointestinal bleeding. Sclerotherapy had proved unsuccessful. She underwent successful liver transplantation. Postoperatively immunosuppression was maintained with cyclosporin $200 \mathrm{mg}$ twice daily and prednisone $10 \mathrm{mg}$ daily. Trough serum cyclosporin concentrations determined by radioimmunoassay remained in the therapeutic range (figure). Within four weeks of the operation results of liver function tests were normal.

Menarche at age 12 had been followed by normal menses, but she had become amenorrhoeic when ill with the repeated gastrointestinal haemorrhages. After transplantation her menstrual periods resumed and were normal for four months. Severe menorrhagia then developed, resulting in anaemia. This heavy menstrua bleeding was not relieved by treatment with a low dose oral contraceptive (ethinyloestradiol $35 \mu \mathrm{g}$ ) but responded to a higher dose $(50 \mu \mathrm{g})$. While receiving this higher dose she developed pruritus and biochemical evidence of intrahepatic cholestasis (figure). Withdrawing the oestrogen promptly relieved her pruritus and normalised the liver enzyme activities, but the menorrhagia returned. A final vaginal haemorrhage was managed with ethinyloestradiol $50 \mu \mathrm{g}$ daily for one week. This second challenge again precipitated pruritus and hepatic dysfunction (figure).

The menorrhagia was controlled by an analogue of gonadorelin, leuprorelin acetate, $1 \mathrm{mg}$ daily, and she was also given transdermal oestrogen (a $50 \mu \mathrm{g}$ patch twice weekly). A normal menstrual cycle was mimicked by giving medroxyprogesterone acetate $10 \mathrm{mg}$ on days $20-27$ of each cycle. This regimen produced regular withdrawal bleeding and stable haemoglobin concentrations and results of liver function tests, and she did not have pruritus.

The patient's family history was non-contributory. The donor of the liver had died from a subarachnoid haemorrhage; she had not had a history of liver disease during any of her pregnancies or when taking oral contraceptives.

\section{Comment}

The resolution of this patient's pruritus and normalisation of biochemical abnormalities after withdrawal of the high doses of oestrogen on two occasions support an aetiological association between the ethinyloestradiol and cholestasis. Further oestrogen treatment was given transdermally to avoid the first pass effect on the liver. She had not received oestrogen before liver transplantation because of the chronic hepatitis. Her age and response to the operation made fertility seem
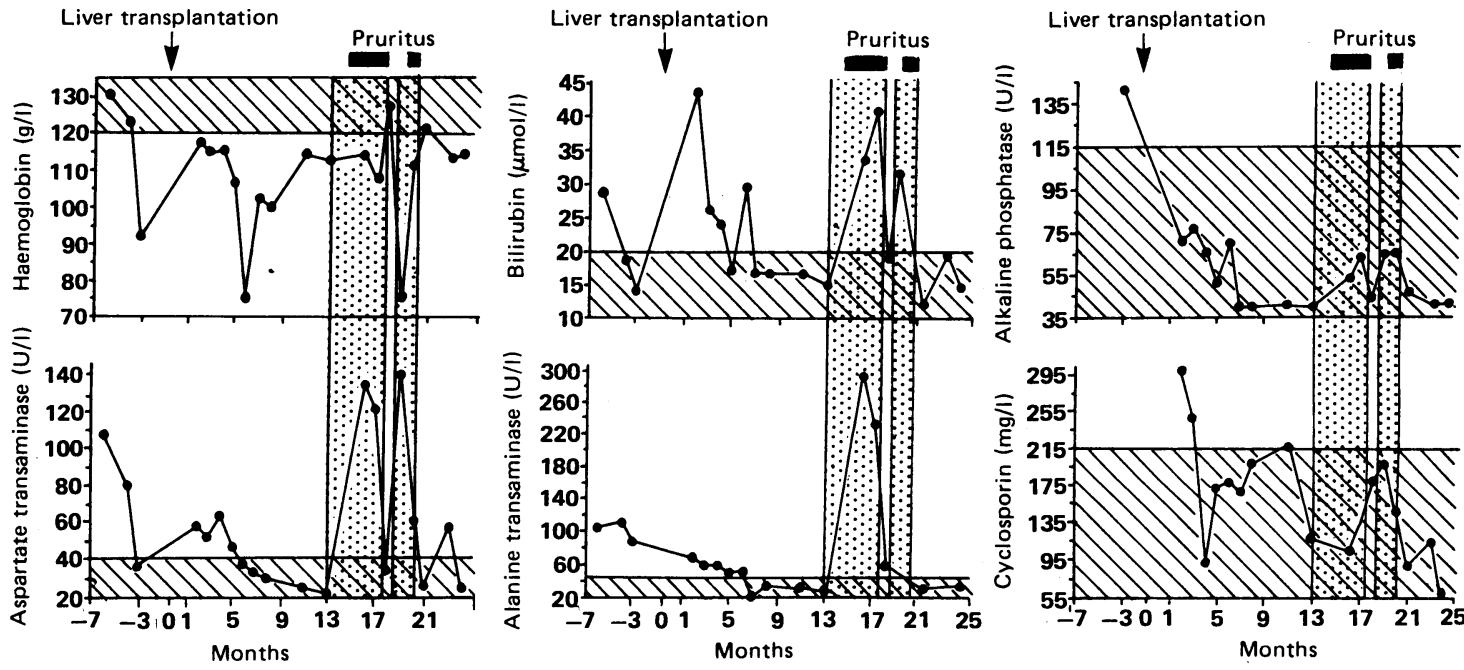

Biochemical concentrations before and after liver transplantation and during administration of ethinyloestradiol (shown by vertical stippled columns). Hatched horizontal areas indicate normal ranges 